\title{
Responding to Change in a Large Organization from a Leadership Angle
}

\section{Rein Coetzee}

School of Human Resources Science, North-West University,

Potchefstroom, South Africa

\section{Jan Visagie}

School of Human Resources Science, North-West University,

Potchefstroom, South Africa

\section{Wilfred Ukpere}

Department of Industrial Psychology and People Management, Faculty of Management, University of Johannesburg, South Africa

\section{Doi:10.5901/mjss.2014.v5n20p827}

\section{Abstract}

The reality today is that organizations and leaders are faced with unrelenting demands to change. Globalisation, competitiveness and ever changing business environments have forced organisations to constantly consider innovative changes. The challenge today is for leaders to be able to reduce the resistance to change, and thus allowing for successful change navigation. It is therefore necessary to be mindful of the various approaches to change in order to ensure that change can be successfully implemented. The success of any change intervention depends on the leadership of the organisation. It is therefore important to note that leadership is an enabler of any type of change. In general leadership can be seen as the driving force to ensure effectiveness and efficiency. Effective leaders know that the successful implementation of change begins with attending to the human side in the organisation. Therefore, leadership is about the leader's ability to influence people and allowing them to change perceptions, behaviours, attitudes and finally action. This paper is an attempt to address specific requirements, referring to relevant leadership competencies and providing more empowering views on the essence of leadership in navigating a successful change intervention.

Keywords: Change, Competencies, Interventions, Leadership, Navigating, Organization, Successful

\section{Introduction}

Change is beyond doubt, the most topical phenomenon of the present moment. The pervasiveness of change is visible in every sphere of human activity. At organisational level the turbulence and rate of change and innovation due to competitive pressures are evident. The reality of change is that it comes in different forms and levels of complexity, and also varies in its extent and significance ranging from nominal to transformational.

The fact remains that change has become more regular and pervasive over the past few years. The pressures of change today in organisations are formidable. The competitive landscape is ever changing. Economic conditions, labour markets, demographics, consumer preferences and especially technological changes affect how business is conducted and managed, in addition to organisations responds to major changes. The pace of change is a major challenge (Herold \& Fedor. 2008). Hence, an ineffectively managed change is likely to pose a huge problem for organisations. However, there seems to be an agreement that the chances of success are greatly enhanced when the human element in the organization are taken into consideration (Taylor, 2001:114). Globally on all fronts, whether politically, economically, socially or organizationally, it appears as if there is an intensifying and growing crisis with regards to leadership. What is not always clear is whether the crisis centres on the institution of leadership itself or the context relative to which leadership has to be demonstrated by the persons exercising leadership.

Owing to differences in micro and macro environmental factors it became critical for South African organizations to renew their basic structures, systems, organisational culture and management practices. International competition, new information, technology and socio-economic changes can be regarded as important factors to be considered when navigating change (Ukpere, 2010). The process of change or transformation is difficult and a long-term effort. However, 
the success of transformation depends on the leadership of an organization. It is only possible to bring about meaningful change if credible and capable leaders lead the change process. Strategic leadership is required for a systematic, planned and controlled change intervention (Nel, et.al. 2011:322). In essence, leadership is the art of getting others to want to do what the leader believes should be done. Leaders gain the confidence of others through their insights, interpersonal influence and their competence. Leadership is not about having the power and influence to command and control the performance of subordinates. It needs to be emphasized that leadership responses exist at all levels in the organisation. Bellingham and O'Brien (2005) correctly refer to leadership as being more about talent and behaviour than only a title and bravado. It is therefore evident that there is a wide range or scope of competencies required in leading change. Thus leaders play an important role as social architects, providing strategic direction, building relationships, establishing culture and values and leading change (Robin \& Judge, 2009). In defining leadership it will be evident that leaders are regarded to be different than other people when they possess outstanding competencies and characteristics. The Leadership environment has changed dramatically over the last few years. The new Leader embraces a new paradigm of change and crisis management, empowerment, collaboration, diversity, higher ethical values and humility (Nel et al., 2011).

\section{Problem Statement}

Leadership competencies are probably one of the most vital issues in contemporary management field. Much has been written already and critics worldwide emphasize remarkable differences. The leadership challenges associated with the world of work today will not only require better but also different leadership competencies to deal with a rapid changing workplace.

\subsection{Research questions}

- What are the current trends of changes taking place in organisations?

- What are the different approaches of responding to change in terms of leadership role in change navigation?

- What leadership styles are necessary in responding to change?

- What are the specific competencies required for a future-fit change leadership?

\subsection{Research objectives}

The objectives of this paper are:

- To explore the current trend of changes taking place in organisations,

- To explore different approaches of responding to change by illuminating the importance of leadership in change navigation,

- To reflect on different leadership styles and patterns necessary to respond to change,

- To identify specific competencies required for a future-fit change leadership.

\section{Literature Review}

The literature review of the paper will be undertaken under this section to enlighten readers with different perspectives of change, change leadership and effective navigation of change.

\subsection{Change defined}

In terms of change, different researchers focus on different concepts, perspectives and forms. Exploring these definitions will help to emphasize the focus of this paper. Ackerman (1986) reflect on developmental change, transitional change and transformational change. On the other hand, Kanter, Stein and Jick (1992) see change as a process that focuses on modifying patterns of behaviour. However, Felkins, Chakiris and Chakiris (1993) perceive change as a process that alters organisational relationship, structures, systems and processes to ensure that the organisation survives.

Veldsman (2008) regards organisational change as the transformation from the current state of the organisation to the desired state. Van Tonder (2004:6) attempts to provide a generic definition when he posits that "change is a process that is dynamic and bound to time and clearly not discrete; change is evident in the state and/or condition within a state of 
an entity; and change... does not occur in void but is bounded by its context." However, King and Anderson (2002) regard change as a phenomenon that significantly influences organisational performance while Jones and George (2003) believe that the success of organisational change resides more in the individual rather than organisational dynamics and refers to critical tasks of managers.

\subsection{Approaches to change}

It is evident that there are contrasting ways to view change and, change efforts in practice do not neatly fall into one approach or the other. The most logical way would be to fully identify the range of approaches that organizations and/or individuals take when implementing change. It is imperative to reflect on the specific frameworks to fully understand different change approaches. Roland and Higgs (2008:31) refer to the four approaches, namely directive, self-assembly, master and emergent. It needs to be mentioned that no single change process ever falls into just one approach. Therefore, different approaches might be needed in different parts of the organisation. Directive change is top down and driven from a single source, such as senior management. Both the outcome and goals and the process of change are determined and developed by the initiating source. Self-assembly change implies that the goals or outcomes of the change are predetermined. However, how a person goes about the change is mainly left to local operating units and teams. Master change approaches are characterised by having a very clear central framework for the change effort, whilst the emergent approach assumes that the organisation is complex and cannot be directly controlled. It is characterised by leaders establishing hard rules to govern what needs to be done.

Green (2007:19) on the other hand distinguishes between five approaches that brings about changes, namely emergence, learning, design, addressing interests and people. Change through emergence means to create the conditions for change to occur without specifying the exact nature of the change. Change through learning is concerned with change happening as a direct result of learning. Change through design most often occurs in organisations and implies the project management approach to change and involves careful planning and detailed analyses. Change through addressing interest addresses the political aspects of organisations, which directly addresses the different needs of the various stakeholders. Change through people recognizes that change in an organisation is predominantly done through people (Van Graan \& Ukpere, 2012; Mdletye, et al., 2012).

Cameron and Green (2009:19) emphasize the behavioural approach focusing on how one individual can change the behaviour of another by using reward and punishment to achieve the intended results. Secondly, the cognitive approach whereby individuals need to look at the way they limit themselves through adhering to old ways of thinking and replacing that with new ways of being. Thirdly the psycho dynamic approach is useful for managers who want to understand the reactions of their staff during a change process and deal with them. It allows them to gain an understanding of why people react to things and use such in the change management process (Mdletye, et al., 2014). Fourthly the humanistic psychology approach combines some of the insights from the previous three approaches while at the same time developing its own insight. Graetz and Smith (2010) provide an extremely detailed and significant framework regarding different approaches to change briefly reflecting on the biological philosophy, which is based on the incremental change within industries rather than individual organizations. The philosophy is developmental in nature, comparing the ongoing stages of progress and change in organizations to organic processes of growth and reproduction. The Rational Philosophy, which is also referred to as strategic, concerns itself with the alignment of an organization's composition, competencies and state over a given time period, within its environmental context (Mdletye, et al., 2013). The Institutional Philosophy makes some fundamentally evolutionary assumptions, but does so in the context of a strong belief in the sensitivity of organizations to the external environments in which they operate.

The resource philosophy is of the view that organizational change begins by identifying needed resources, which can be traced back to sources of availability and evaluated in terms of criticality and scarcity. An understanding that a dependence on resources increases uncertainty for organizations is particularly useful in change efforts, because it encourages an awareness of critical threats and obstacles to performance (Coetzee, et al., 2013). The contingency perspective is based on the proposition that organizational performance is a consequence of the fit between two or more factors, such as an organization's environment, use of technology, strategy, structure, systems, style or culture. The psychological philosophy is based on the assumption that the most important dimension of change is found in personal and individual experience when referring to organizational development and change transitions. The political philosophy assumes that it is the clashing of opposing political forces that produce change, and therefore explains change as the result of clashing ideologies or belief systems (Werner, et al., 2007).

In addition, the cultural philosophy believes that change is normal in that it is a response to changes in the human environment where this process is natural, leading to the construction of firm ways of thinking about how things should be 
done. However, the systems philosophy is of the view that any imposed change has numerous and sometimes multiplied effects across an organization and consequently, in order for change management to be successful, it must be introduced across the range of organizational units and sub-systems. The postmodern philosophy is described as one that is comfortable with ephemerality, fragmentation, discontinuity and chaos, but also seeks to take action rationally toward ongoing improvement". These 10 philosophies illustrate the distinctiveness in different situations or set of events. These different philosophies focus on the complementary and competitive forces that organizations face in managing the tension between continuity and change (Coetzee, et al., 2012a).

In view of different approaches to change as outlined above it is evident that attention must be paid to the different views on implementing a change intervention. Lately there have been worldwide intensive debates on the critical issues of managing change; leading change and navigating change (Coetzee, et al., 2012b). Many authors regard these as pure semantics. However, this paper has adopted the concept of leading change. There is no doubt that managing change focuses more on planning, organizing, coordinating and controlling aspects of change. However, successful change lies with the kind of leadership.

\subsection{Leading change Defined}

The concept of managing change has been around for a long time in a typical closed-system view of the organisation. In this regard, Van Tonder (2004:197) has stated that "change can be managed in one best way and that such change management programmes will ensure that loss of production and performance as a result of change can be corrected swiftly and without complications". He further stated that "... this view of change management as a planned, purposive and controlled activity (and change being amenable to such activities) has been criticised owing to the fact that it can only be conceived from within a closed-systems perspective, which a situation of environmental stability that was more prevalent during the 1960s than in the current moment. It is now commonly acceptable that such rigid and structured programmatic approaches for dealing with change will no longer suffice in the rapidly changing and turbulent environments in which organisations now have to adapt and evolve."

From the above literature, it is essential to summarise the various approaches for dealing with change. Van Tonder (2004) maintains that remedies for change implementation are presented as a set of different steps and that there is no difference in the essential ingredients of such steps or processes as reflected in Table 1 below.

Table 1: Implementation of change

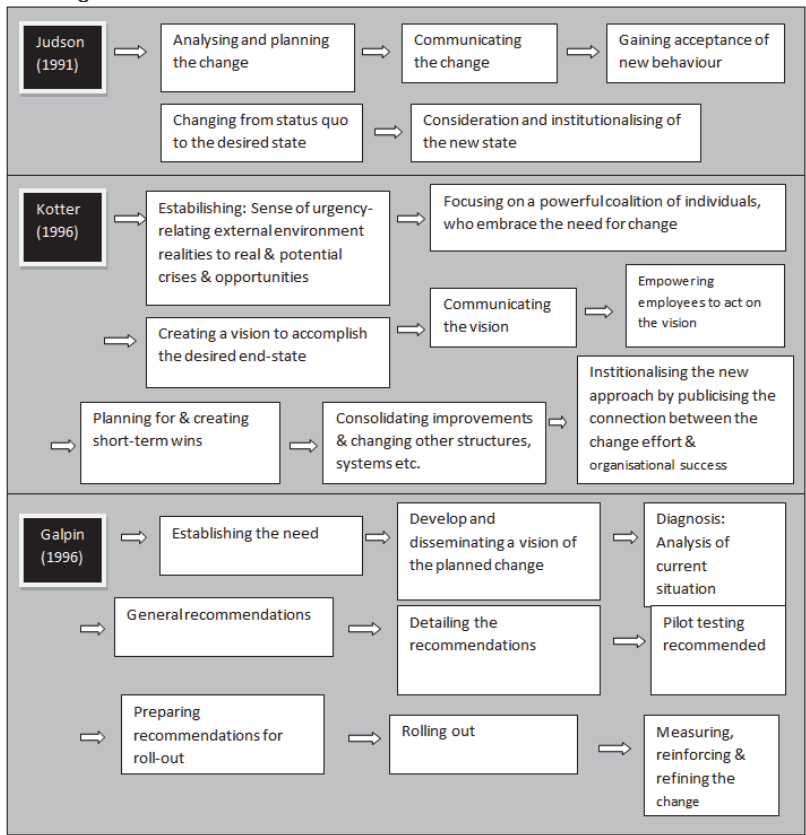

Source: Van Tonder (2004:200). 
Following the review of the more traditional ways of managing change it is important to look at a more modernistic approach to change management, an approach that place the emphasis on leading change as opposed to managing it. In doing so, some definitions and explanations are worthwhile. For instance, Achua and Lussier (2010:386-387) summarise leading change by positing that there is a growing interest in understanding how to increase the success rate of change initiatives. Experts stress the importance of leadership involvement throughout the process. Leadership must make every effort to eliminate policies, procedures, and behaviours that undermine the change efforts. Followers who are charged with implementing change must see in the behaviour of their leaders an honest effort to share in the challenges of the change. The leader must be willing to alter his or her behaviour in order to minimize resistance to change efforts. Effective listening helps a leader to have a better understanding of the root causes of resistance. They further maintained that the role of the leader is to implement change that results in better organizational performance. However, the question has always been how to do it effectively and successfully, given the stress, discomfort and dislocation associated with it.

Griffin and Moorhead (2006) emphasize the importance of the influence component of leadership. They stress the importance of the influence the leader has on followers as opposed to characteristics of the leaders when implementing large change interventions. The ability of the leader to influence others is the cornerstone to lead change successfully. They also mentioned three specific changes that can ultimately lead to success, namely change in perception, which is to realize that the current working conditions are more hazardous than it is believed to be. Change in attitude, which implies that the organisation will be a far better place to work in than before. Change in behaviour, which means that a person works harder and/or get others to work harder. There are also those that are of the opinion that a multi-dimensional approach to leading change is required. They reject the view that either n-step goal directed models of change management or the more humanistic $21^{\text {st }}$ century leadership with a more participative inclusive style is required.

In their treatise Graetz and Smith (2010) observed that the challenges facing change leaders today is their ability to implement systems that can cope with ambiguity, ambivalence and contradiction. They further posited that a multiphilosophy approach reinforces the need to discard assumptions about opposing values and replacing them with an appreciation of complementary concepts. Flexibility is crucial in a turbulent environment in order to find new ways of doing things (innovation). However, order is necessary to ensure that innovation is relevant. From the above, it is observed that aspects of leading change are common. Therefore, the traditional change management steps or processes can no longer be applied as a recipe. Thus, a combination of system and goal directed change models and humanistic and inclusive leadership models are necessary. Consequently, leading change is widely accepted as opposed to managing change. More than that, change is more receptive once the leaders are committed and honest towards the change interventions, and to lead change is to be able to influence people to change their perception, attitude and behaviour.

\subsection{Leadership styles}

Transformational and transactional leadership styles are categorized as the new leadership paradigms and are linked to charismatic and strategic leadership (Durungs-Ruhier, 2011). Transactional leadership emphasise the importance of the relationship between a leader and his/her followers and is less concerned with the transformation of the organisation. Transformational leaders set high goals of change and take responsibility for their commitments. Hence, they are concerned with collective well-being and can inspire and motivate their followers to cross their comfort zone in order to go beyond their potentials. Derungs-Ruhier (2011:53) refers to four 'i's in transformational leadership namely, Idealized influence, which is that a leader is a role model for others; Inspirational motivation, meaning that a leader provides meaning, vision and hope; Intellectual stimulation, which means that a leader stimulates creativity and innovation; Individual consideration, which is to say that a leader is concerned with the individual needs of subordinates.

Hughes (2007:148) refers to transactional leaders as leaders who "guide or motivate their followers in the direction of established goals by clarifying role and task requirements. Whereas transformational leaders change followers' awareness of issues by helping them to look at old problems in new ways, where they are able to excite, arouse and inspire followers to put out extra effort to achieve group goals". According to Isaksen and Tidd (2006:125) a transactional style "...is a mutual influence between leaders and followers working on the basis of a reciprocal exchange relationship of costs and benefits. Decision-making takes place in a stable and certain framework where bureaucratic authority, formal rules, regulation, procedures and legitimate power are all visible and regularly exercised. Transformational leadership is based not on physical rewards but on motivation. Transformational leaders often initiate and implement changes in the structure and strategy of the business and towards people". A modernistic approach to leadership styles was highlighted by Pearse (2011) by referring to patterns of leadership actions. In terms of these patterns he posited that leadership patterns should not simply be interpreted as leadership styles but as patterns arising due to the interaction between 
leaders and their context over a particular period of time. The six patterns have been identified. The first three is referred to as effective patterns while the last three as ineffective patterns and describe in the following terms, namely freewheeler, which refers to an organisation that is already in the process of moving in the direction of the desired change, where the leader maintains the momentum; focused pioneer is a situation where the leader need to push ahead with the planned change and ensure that all systems and processes are aligned. Reflexive accommodator is a situation where the leader is required to slow down the pace of the change slightly to accommodate the needs and concerns of the followers. This particular pattern in conjunction with the focused pioneer is important to successfully lead the change. Rigid combatant occurs where there is excessive force for people to embrace change. It can also be viewed where caution is not applied during the focus pioneer pattern; popular people pleaser is exactly the opposite to the abovementioned patterns, whereby the leader accommodates the concerns of the followers at the expense of the change. Static non-leader occurs when there is no or limited influence by the leader. There is a lack of communication on progress and the vision/goals are not regularly reinforced, which results in subsequently the loss of the momentum.

An interesting view is provided by Matthew (2009:7), when he refers to creative leadership. "Creativity has been linked to the function of leading change in the propulsion model of creative leadership. According to the theory, significant organizational change requires a type of creative leadership that rejects current ways of doing things and proposes new assumptions or paradigms. Leading organizational change is perceived as a creative function that fundamentally influences change in individual and group behaviour in an organization. Hence, leader creativity is expected to predict the capacity to lead change. Since leading change involves understanding and working with a range of basic human needs on multiple levels (i.e., individual, group and organizational), social-emotional competency is expected to have a direct effect on the capacity to lead change." Puccio, Mance and Murdock (2011) support this view and remarked that highly creative leaders always challenge the status quo, take risks, experiment with new approaches and examine alternative ways of solving problems. Therefore, creative leaders always focus on future possibilities and think in terms of what is possible and might be adept at getting others to buy-into their ideas. It is evident that creativity as related to leadership practices becomes crucial in terms of bringing creative and innovative change to an organisation.

\subsection{Challenges in leading change}

There exist differences in opinion in business today regarding the phenomenon of change management versus leading change. For instance, Veldsman (2008:216) beliefs that leadership is one of the most important elements and in this regard mentions some top change implementation challenges in order of importance, namely employee resistance, leadership issues, planning issues, communication failures, culture, skills issues and industrial relations issues. It is important to note that successful change in large organisation should be implemented according to a holistic plan. Change leaders often try to balance two countervailing forces namely the need to drive change through their organisation in order to respond to ever changing environments and seeing the importance of incorporating what they know about the human aspects of change. In this respect Herold and Fedor (2008:112) suggest that leader should note that organisational changes cannot be contemplated as independent and isolated events. Hence, all changes cannot at the same time be first priority and leaders must take a more strategic view. It must also be kept in mind that no matter how carefully leaders contemplate a given change, the actual benefits will be a function of the change environment in which it is embedded. Therefore, the challenge associated with a given change will increase exponentially as the environment in which the change is to be embedded becomes more turbulent, because individuals differently to turbulence changes. To that end, senior leadership should be committed in its role in orchestrating the various change initiatives.

In order to successfully lead change, Spiro (2011:5) suggest eight steps to overcome the challenges of leading change, namely determine the change strategy by defining it specifically with timelines; assess readiness by improving the readiness of all parties; analyze the stakeholders by making an effort to understand the motivation levels of all stakeholders; minimize resistance by assessing individual's own tolerance; secure a small early win by planning and securing an incremental early win to convince stakeholders; engage the key players in planning skilfully to bring together all internal and external players; scale and sustain the change strategy which entails sustaining the initiative over time; build in ongoing monitoring and effect corrections by determining whether the change strategy solved the original problems.

\section{Research Design and Methodology}

This paper is based on mixed method design. While there are various definitions for mixed method, the definition of Tashakkori and Teddlie (2009:286) is sufficient for the purpose of this paper. They defined mixed method research as, 
"... research in which the investigator collects and analyses data, integrates the findings and draws conclusions using both qualitative and quantitative approaches in a single study". A mixed method design is suitable for this research because it allows the researcher to gain complementary insights in terms of conceptualising of the relative contributions of leadership in change navigation. In addition, it provides a more complete and meaningful picture of the nature and dynamics of leading change. For instance, an initial qualitative research approach allows the researcher to refine the initial research proposition which was letter analysed quantitatively. It also allowed the researcher to expand on the initial understanding of leadership, in order to provide a more comprehensive explanation at a latter phase in the research process. It provides the opportunity to assess the credibility of the inferences that are drawn during one phase and thereby supports the credibility of inferences that are made at latter phases in the research. In terms of the qualitative sample, a convenient sample of 5 senior leaders was selected. A semi structured interviews were conducted and digitally recorded. Content analysis of verbal response was undertaken to identify and verify different dimensions. In terms of the quantitative method, one of the divisions in the company was purposefully selected. A survey questionnaire was developed and first of all piloted at the company amongst a number of non-randomly selected employees who were not part of the focus group. Then feedbacks from the pilot study were used to revise the contents of questionnaires before they were distributed to 301 employees for response. A comparative statistics to identify differences and similarities was applied during the data analysis.

\section{Discussion of Findings}

\subsection{Phase 1: Qualitative findings}

With regards the question of the initial reaction to change the five participants agreed that initially there was a reaction of uncertainty, uncomfortableness, anxiety as well as a feeling that "we do not need this in our lives right now". Also important to note is the fact that there were different levels of uncomfortableness on the various levels of staff. This reaction to the envisaged change was to be expected and the question was posed to the participant whether the need and reasons for change was clearly communicated. All five participants responded positively to this question. However, one participant felt that, "it could have been done better". The participant mentioned that a consistent message, the language barrier as well as the "emotional message" could have been executed better. One participant highlighted the importance of explaining the possible consequences had the leaders ignored the need for change. In terms of the method of communication, all participants stated that it was a top down approach. They stated that the company has clearly defined structures and these were utilized to ensure that the message reached all employees at the right time. Newsletters, individual and group discussions, DVD communication as well as road shows were major source of communication. All the participants concurred that where possible the communication was made interesting and exciting.

Focusing on the leadership aspect of the change the participants were asked what guidance and support they provided during the change process? All the participants agreed that sufficient support were provided and the way in which this was achieved are summarised as follows: a lot of communication to ensure understanding and buy in, reinforcement of certain ethics such as reliability, trustworthiness and ensuring that staff understand the fact that leaders are there for them. In addition, HR aspects such as voluntary early retirement, retention policies and retraining and upskilling of staff were offered. In addition to the above the participants were asked to identify the most crucial aspects for leadership to implement change. There were a lot of similarities from the participants' response and the three most important aspects were, firstly, the ability to set and communicate a vision, strategy and the ability to execute the strategy. Secondly, the leader's ability to embrace the change and equally be prepared to change was highlighted. Thirdly, to be transparent and energetic, engaging, enabling and empowering the people you are taking on the journey of change. The final question was related to the competencies that the participants identified in leaders when leading a change intervention. The participants agreed unanimously that it is all about work ethics and values and they summarised this with the following: trust, consistency, commitment, building and maintaining relationships, transparency, honesty, integrity, openness, courage, creativity, granting people their space as well as emotionally connecting with people.

\subsection{Phase 2: Quantitative findings}

Figure 1 below reflect the responses of employees regarding change, how the envisaged change was perceived, how the change was communicated as well as the initial reaction of employees towards the change initiatives. The following relevant questions were posed to respondents:

Question 9: You understood the need for change 
Question 16: The intended change was experienced as a threat.

Question 18: All stakeholders supported the intended change.

Figure 1: Summary of employee responses

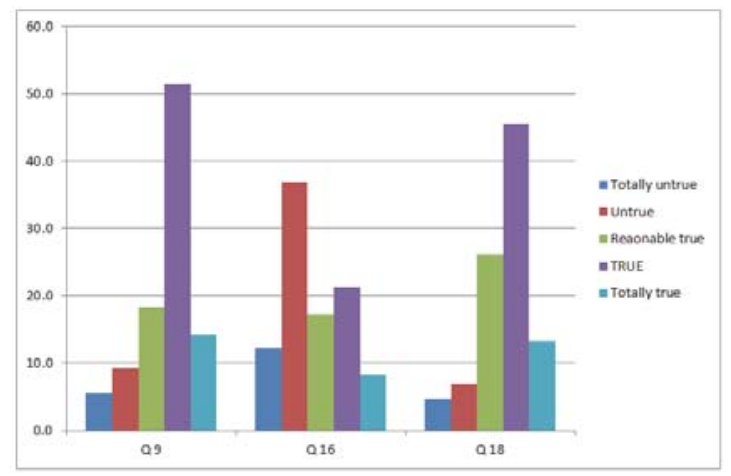

Source: Authors' Fieldwork.

Figure 2 below dealt with the relevant questions, which deals with leading change. The following questions posed to respondents:

Question 15: The intended change was regularly communicated.

Question 28: You believed the leaders made the right decision to decouple financial services and traditional retail. Question 29: You had confidence that the leaders in the organisation could succeed with the change.

Question 31: The leaders themselves were committed to the change.

Figure 2: Summary of employee responses Source: Authors' Fieldwork

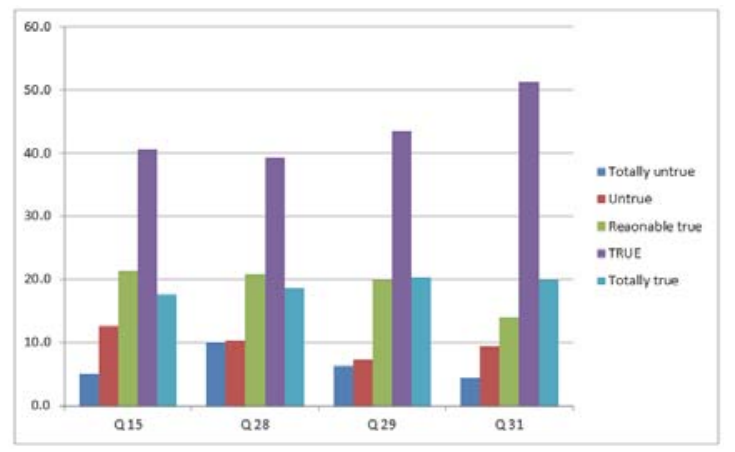

\section{Source: Authors' Fieldwork}

Figure 3 below posed questions pertaining to specific leadership participation in order to determine whether the change was properly navigated by the leaders:

Question 25: You were informed on the end results of the intended change.

Question 26: You were informed of the benefits of the change.

Question 29:.You had confidence that the leaders in the Organisation could succeed with the change.

Question 30: You received the necessary guidance during the time of change. 
Figure 3: Summary of employee responses

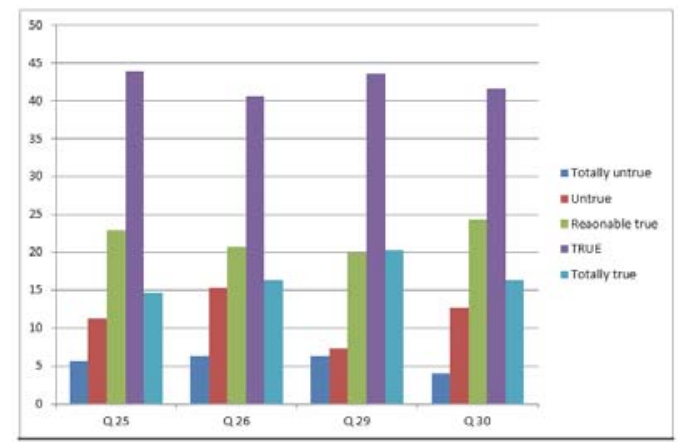

Source: Authors' Fieldwork.

\section{Discussion of Findings}

With regards to question 9 , which relates to the understanding of the need to change, the majority of the respondents $(65.8 \%)$ indicated that they agree. That was followed by the question whether they felt threatened by the change (question 16). In that regard, the theoretical research supported a natural resistance to the unknown. Therefore, the qualitative results supported this, in that $46.9 \%$ of respondents indicated that they felt threatened initially. Question 18 dealt with the matter of limiting the initial response to change and posed a question on the support or the absence thereof in terms of the envisaged change. The majority of the respondents (58.8\%) felt that they supported the envisaged change as compared to only $11.7 \%$ who indicated that they did not support the envisaged change. Senior Management was of the opinion that even though the change and the reasons behind it were explained, it could have been done more and better. In contrast, the majority of the respondents $(58.1 \%)$ were of the view that there were regular communications during the change process. Questions 28, 29 and 31 dealt with leadership during the change intervention. On the question pertaining to whether the leaders made the correct decision, $78.7 \%$ of respondents felt that they did as indicated in figure 2 above.

During the qualitative research one of the senior leaders mentioned that if there is no change the organisation will become a "healthy dinosaur". The respondents did not only support the leader's decision, but also displayed substantial trust in their abilities to successfully implement the change (83.7\% responded positively to question 29). The respondents were asked about the leaders' commitment to the change and $85.1 \%$ of them felt that the leaders were committed to the change. This was supported by the view of senior Management. Finally there was a set of four questions that dealt with the issue of change navigation. Questions 25 and 26 dealt with information sharing (communicate the results and benefits of the change) and the majority of the respondents ( $81.4 \%$ and $77.4 \%$ respectively) felt that there were sufficient feedbacks. There was a clear sense of confidence in the leaders in that $83.7 \%$ of respondents answered positively to question 29. Guidance and support were highlighted by senior leaders as crucial aspects in change navigation. In this regard the respondents felt that there were ample guidance (82.1\%) provided by the leaders during the change process.

\section{Conclusion}

In conclusion, rapid changes will continue to hit organisations in the $21^{\text {st }}$ century and beyond. However, resistance to change is human nature. However, the world cannot run away from changes because the world is always changing into change, as it once was from the beginning of time. Therefore, the challenges triggered by change will necessitate an effective leadership to navigate it successfully in a large organizational setup. In other words, in order to successfully navigate and implement change, leaders should strive to possess the necessary leadership ethics of consistency, commitment, relationship building, transparency, honesty, integrity, trust, openness, courage and creativity. In a nutshell change leaders in a large organisation and any organisation for that matter, should be emotionally intelligent. 


\section{References}

Achua, C. F., \& Lussier, R. N. (2010). Effective Leadership. USA: Cengage Learning.

Ackerman, L. S. (1986). Development, transition or transformation: the question of change in organisations. OD Practitioner, 18(4), 1-9.

Bellingham, R., \& O'Brien, W. (2005). The Leadership Lexicon. Amherst. HRD Press.

Bester, C. (2012). Live \& Lead. Johannesburg, South Africa: Porcupine Press.

Binney, G., Wilke, G., \& Williams, S. C. (2005). Living Leadership. Harlow, UK: Pearson Education Limited.

Bohlander, G. W., \& Snell, S. A. (2010). Principles of Human Resource Management. South-Western, USA: Cengage Learning.

Burnes, B., \& Oswick, C. (2012). Change Management: Leadership, Values and Ethics. Journal of Change Management, $12(1), 1-5$.

Coetzee R, Visagie J, Ukpere WI. 2012a. Leading a successful change intervention in a modern organisation: Key elements to consider. African Journal of Business Management, 6(51): 12068-12075.

Coetzee R, Visagie J, Ukpere WI. 2012b. Leadership challenges in change intervention and navigation. African Journal of Business Management, 6(51):12076-12085.

Coetzee R, Visagie J, Ukpere WI. 2013. A Proposed Leadership Competency Model for Effective Organisational Change Intervention. J Soc Sci, 36 (3), 247-253.

Cameron, E., \& Green, M. (2009). Making sense of change management: A complete guide of the models, tool and techniques of organisational change. London, England: Kogan Page limited.

Cohan, P. S. (2003). Value Leadership: The seven principles that drives corporate value in any economy. San Francisco, California: Jossey-Bass.

Derungs-Ruhier, I. M. H. (2011). Trans-cultural leadership for transformation. United Kingdom: Macmillan Publishers.

Dubrin, A. J. (2007). Leadership: Research findings, practice and skills. Boston, USA: Houghton Mifflin company.

Felkins, P. K., Chakiris, B. J., \& Chkiris, K. N. (1993). Change management: a model for effective organizational performance. New York, NY: Quality resources.

Graetz, F., \& Smith, A. C. T. (2010). Managing Organizational Change: A Philosophies of Change. Journal of Change Management, 10(2), 135-154.

Green, M. (2007). Change management: A step by step guide to successful change management. London, England: Kogan Page.

Griffin, R. W., \& Moorhead, G. (2006). Fundementals of organizational behavior: managing people and organizations. USA: Houghton Mifflin Company.

Herold, D. M., \& Fedor, D. B. (2008). Leading change management: Leadership strategies that really work. London, England: Kogan Page.

Hewitt ML, Ukpere WI. 2012. Leadership challenges associated with the management of Generation $Y$ employees: A proposed theoretical model. African Journal of Business Management, 6(19):5999-6004.

Hughes, M. (2007). Change management: a critical perspective. London: CIPD House.

Isaksen, S., \& Tidd, J. (2006): Meeting the innovation challenge: Leadership for transformation and growth. West Sussex: John Wiley \& Sons.

Jones, G. R., \& George, J. M. (2003). Contemporary Management. New York, NY: McGraw-Hill.

Kanter, R. E., Stein, B., \& Jick, T. D. (1992). The challenge of organisational change: how companies experience it and leaders guide it. New York, NY: The Free Press.

King, N., \& Anderson, N. (2002). Managing innovation and change: a critical guide for organisations (2nd ed.). London, England: Thompson.

Lussier, R. N., \& Achua, C.F. (2004). Leadership theory: Application and skill development. South-Western, USA: Thomson Corporation.

Matthew, C. T. (2009). Leader Creativity as a Predictor of Leading Change in Organizations. Journal of Applied Social Psychology, 39(1), 1-41.

Mdletye AM, Coetzee J, Ukpere WI. 2012. The Impact of transformational change in the Department of Correctional Services of South Africa. African Journal of Business Management, 6(50):11986-11998.

Mdletye MA, Coetzee J, Ukpere WI. 2013. Emotional Reactions to the Experiences of Transformational Change: Evidence from the Department of Correctional Services of South Africa. Mediterranean Journal of Social Sciences, 4 (14), 501.

Mdletye MA, Coetzee J, Ukpere WI. 2014. Organisational Identity: Another Key Consideration for Facilitating Effective and Efficient Transformational Change - Lessons from the South African Department of Correctional Services. Mediterranean Journal of Social Sciences, 5 (3), 190.

Nel, P., Werner, A., Du Plessis, A., Ngalo, O., Poisat, P., Sono, T., Van Hoek L., \& Botha, C. (2011). Human Resource Management. Cape Town, South Africa. Oxford University Press.

Pearse, N. J. (2011). Effective strategic leadership: Balancing roles during church transitions. HTS Teologiese Studies/Theological Studies, 67(2), 1-7.

Pretorius, B. 2013. In the driving seat: lessons in Leadership. South Africa. Tafelberg Publishers.

Puccio, G. J., Mance, M., \& Murdock, M. C. (2011). Creative Leadership: Skills that drive change. California, USA: Sage Publications.

Robbin, S.P. \& Judge, T.A. (2009). Organizational Behavior. New Jersey: Person Prentice Hall.

Rowe, W. G., \& Guerrero, L. (2011). Cases in Leadership. California, USA: Sage Publications.

Rowland, D., \& Higgs, M. (2008). Sustaining change: Leadership that works. Calif, San Francisco: Jossey-Bass.

Spiro, J. (2011). Leading Change: Step-by-step. San Francisco: John Wiley \& Son. 
Tashakkori, A., \& Teddlie, C. (2009). Integrating qualitative and quantitative approaches to research. In Bickman, L., \& Rog, D.J. (Eds.). The SAGE handbook of applied social research methods. (2nd ed.) (pp. 283-317). Los Angeles, LA: Sage publications.

Taylor, S. (2011). Contemporary issues in Human Resource Management. London: Chartered institute of personnel and development. Ungerer, M., Heroldt, J., \& Le Roux, J. (2013). Leadership for all: Virtue practices to flourish. Randburg, South Africa: Knowres Publishing.

Ukpere W.I. (2010). The Negative impacts of globalization logics on labour Markets, Indian Journal of Economics, 359 (4): 2010.

Van Dijk, R., \& Van Dick, R. (2009). Navigating Organizational Change: Change Leaders, Employee Resistance and Work-based Identities. Journal of Change Management, 9(2), 143-163.

Van Graan J, Ukpere WI. 2012. An Inclusive Approach to Structural Transformation in Organisational Restructuring. African Journal of Business Management, 6(50):11916-11922.

Veldsman, T. H. (2008). Into the people effectiveness: navigating between chaos and order. Randburg, South Africa: Knowledge Resources.

Von Tonder, C. L. (2004). Organisational Change. Theory and practice. Pretoria, South Africa: Van Schaik Publishers.

Werner, A., Bagraim, J., Cunningham, P., Potgieter, T., Viedge, C. 2007. Organisational Behaviour: A contemporary South African perspective. Pretoria: Van Schaik. 